\title{
Proceeding
}

Supplementary Issue: Winter Conferences of Sports Science. Costa Blanca Sports Science Events, 22-23 March 2021. Alicante, Spain.

\section{The impact of an extracurricular outdoor physical activity program on long-term memory in adolescent during COVID-19 pandemic}

\author{
FRANCESCA LATINO ${ }^{1}$, MICHELE DE CANDIA ${ }^{1} \triangle$, MILENA MORANO², ROBERTO CARVUTTO $^{1}$ \\ ${ }^{1}$ Department of Basic Medical Sciences, Neuroscience, and Sense Organs, University of Bari "Aldo Moro", \\ Bari, Italy \\ 2School of Medicine and Health Sciences, University of Chieti-Pescara "G. D’Annunzio", Chieti, Italy
}

\begin{abstract}
The present study examined the effects of an 8-week extracurricular outdoor physical activity program aimed to improve long-term memory performance in adolescent concerning the Covid-19 period. Participants were 40 schoolchildren (aged 16-17) who trained twice a week in aerobic exercise two hours per session, randomly assigned to participate in either an extracurricular outdoor physical activity program ( $E G ; n=20$ ) or a waitlist control group (CG; $n=20)$. At baseline and after training we administered the Verbal Paired Associates (VPAI) a subtest of the Wechsler Memory Scale - IV (WMS-IV, 2009), which represents one of the most widely used instruments for assessing explicit episodic memory performance. The results suggested that after 8week aerobic exercise program students were able to increase their long-term memory, and that this capacity was more evident following physical activity that required greater cognitive involvement.

Keywords: Exercise; Cognitive functioning; Physical education; Aerobic exercise.

\section{Cite this article as:}

Latino, F., De Candia, M., Morano, M., \& Carvutto, R. (2021). The impact of an extracurricular outdoor physical activity program on long-term memory in adolescent during COVID-19 pandemic. Journal of Human Sport and Exercise, 16(3proc), S1114S1125. https://doi.org/10.14198//hse.2021.16.Proc3.28
\end{abstract}

Corresponding author. Department of Basic Medical Sciences, Neuroscience and Sense Organs, School of Medicine, University of Study of Bari, Lungomare Starita 1, 70123 Bari (BA), Italy.

E-mail: michele.decandia@uniba.it

Abstract submitted to: Winter Conferences of Sports Science. Costa Blanca Sports Science Events, 22-23 March 2021. Alicante, Spain.

JOURNAL OF HUMAN SPORT \& EXERCISE ISSN 1988-5202.

(c) Faculty of Education. University of Alicante.

doi:10.14198/jhse.2021.16.Proc3.28 


\section{INTRODUCTION}

Outdoor physical activity has always been associated with improvements to physical health and mental wellbeing. It helps to prevent many psycho-physical health conditions by enhancing certain physiological mechanisms in both healthy and illness (Fischetti et al., 2019; Thompson Coon et al., 2011). Physical activity in natural environments not only facilitates enjoyment for participants and improves adherence but may also encourage positive behaviors which are likely to produce greater cognitive gains (Lahart et al., 2019). Engaging in physical activity outdoors seems especially important for adolescent as it represents a stimulating setting for both motor and cognitive development (Latino et al., 2021; Notarnicola et al., 2012). Moreover, engagement with nature provides a manifold of human interactions and learning of social skills (Wray et al., 2020).

The COVID-19 pandemic has caused an unprecedented lockdown worldwide, resulting in social isolation due to the recommendation for people to stay at home in quarantine to prevent the spread of this viral disease (Lesser, \& Nienhuis, 2020). For over a year now, our kids are forced to remain closed in the house, unable to meet their friends, go to school, and experience one of the most important phase of growth: the adolescence. A delicate and meaningful time for the personal psycho-physical development that, if it is not properly supported, would create irreparable damage (Bonavolontà et al., 2021a).

Physical activity has always been considered of paramount importance young people's growth (Morano et al., 2020). This awareness emerges more clearly and urgency in this particular historical period in which the reduction of social relationships and physical inactivity are grafted on a daily life already distinguished by an excessive use of internet and social networks (Bonavolontà et al., 2020; Pinho et al., 2020). Global estimates indicate that now as never before adolescents do not meet the 2020 World Health Organization (WHO) recommendations for physical activity. These preventive measures have caused several impacts on society, such as on education, and on adequate levels of physical activity (Dwyer et al., 2020). In fact, multiple lines of research suggested that a direct correlation between physical activity and cognitive performance exists (Donnelly, 2016; Erickson et al., 2019; Singh et al., 2019). The mechanisms through which physical activity may improve cognition involves increasing blood and oxygen flow to the brain (Jorgensen et al., 2000), levels of norepinephrine and endorphins (Bidzan-Bluma, \& Lipowska, 2018; Fleshner, 2000), resulting in a decrease of stress, and growth factors that support synaptic plasticity and help to create neurogenesis phenomenons (Cassilhas et al., 2016). Specifically, aerobic physical activity, including that activity performed in open air, is able to increases blood flow to important learning areas of the brain, induces positive changes in brain structure, and improves performance of brain regions that are responsible for memory (Erickson et al., 2011; Voss et al., 2019; Zuniga et al., 2019). One aspect of cognition that appears particularly sensitive to a regular aerobic exercise is long-term memory (Labban, \& Etnier, 2018; Pyke et al., 2020). Concerning that, a large body of literature suggests that regular aerobic physical activity engagement appears to improve neural structures that facilitate the storage of explicit information in long-term memory (Cooper et al., 2018; Hötting, \& Röder, 2013; Voelcker-Rehage, \& Niemann, 2013). It was hypothesized that an exercise-induced increases in the amount of available resources has an impact on memory storage capacity, thereby promoting learning outcomes (Khan, \& Hillman, 2014). Moreover, green physical activity experienced in natural dynamic environments, deeply activates cognitive processes involved in encoding and retrieving information (Pesce et al., 2009; Williams et al., 2000).

In the light of what was discussed, the potential enhancement of memory function from exercise-related has numerous implications in academic achievement. Therefore, the relationship between physical activity and cognitive outcomes, such as school performance is extremely significant because the level of education is 
an important predictor of quality of life (Donnelly et al., 2016). At this time, outdoor exercises in the means of improving both motor and cognitive performance overstretched by the inactivity, is more necessary than ever. Today, training in open air is the unique opportunity not only for increasing general well-being and maintaining social relationships, but it also represents a positive way to improve academic outcomes. Despite the need to keep safety physical distancing and all the measures provided to contain the contagion, physical activity performed in open-air could be an optimal way to establish a positive and healthy routine both for the physical and mental well-being (Park et al., 2020). Thus, green exercise may be a useful natural medicine to address these challenges facing world countries.

On the one hand the scientific studies conducted in this area are numerous, but they are mainly focused on the elderly where the effects of physical activity may be more evident due to age-related degradation of memory, and on the potential risk of injury. For this reason, preventive motor interventions are required both for neuropsychic (McEwen et al., 2018; Roberts et al., 2017), and physical injury risks (Bianco et al., 2014; Bonavolontà et al., 2021b; Patti et al., 2021). On the other hand, not enough it was done concerning the relationship between aerobic physical activity and memory in youth. Therefore, to extend the knowledge in this research field, the purpose of this study was to assess the impact of an outdoor physical activity program on long-term memory, an important aspect of cognition that represents a positive way to improve academic performance, at the time when adolescents have to observe forced rest due to Covid-19 confinement, risking the worsening of athletic performance and suffering postural disorders that require special interventions (Greco et al., 2019). Specifically, we focused on adolescence because youth are increasingly complaining about depression and isolation that more and more often results in negative behavior, but above all because we believe that adolescence is an important period for establishing healthy habits for the construction of the body image (Latino et al., 2019), and a functional physical suitable for maintaining physical athleticism (Fischetti et al., 2019a,b).

\section{METHOD}

\section{Study design}

In this research, a randomized controlled study design was used to investigate the effects of an 8-week extracurricular outdoor physical activity program on long-term memory, at the time when students must observe a forced rest because of the Covid-19 confinement. The study was conducted in a local green park consisted of 16 lessons of supervised aerobic exercises. The interventions were performed for 120 minutes 2 days per week at the end of the daily school lessons. Training sessions were conducted in the evening from $2.30 \mathrm{pm}$ to $4.30 \mathrm{pm}$ on Tuesday and Thursday. Measurements were administered 1 week before training (pre-test) and directly after training (post-test).

\section{Participants}

We randomly assigned 40 healthy male and female adolescent students of 16-17 years (24 males and 16 females; $M$ age $=16.3 ; S D= \pm 0.51$ ) to either an experimental group who practiced an Extracurricular outdoor aerobic training, or a wait-list. Participation in the research study was voluntary and all high students from the local school were eligible to participate in this study. Inclusion criteria were the following: participants had to be relatively healthy individuals capable of completing a moderate-intensity aerobic exercise session and able to abstain from all physical activity outside the parameters of the study protocol. From the study were excluded any students with an orthopedic condition limiting their ability to perform exercises, and those unable to abstain from all physical activity outside the confines of the study protocol on the testing days. 
The participants included in the control group were informed that they were on a waiting list for participation in the exercise program and were asked to complete the data collection initially and at eight weeks, before being allocated to the intervention condition. The study was conducted from September to November 2020. All participants and their parents received a complete explanation in advance about the purpose of the experiment, its contents, and safety issues based on the Declaration of Helsinki, and parents of all participants provided their written informed consent before the study.

\section{Procedures}

The intervention program was administered in a local green park at the end of the daily school lessons. Each session of the intervention program involved the following stages: warm-up for 10 minutes, perform the main exercises for 50 minutes, a game or dance session for 50 minutes, and cool down and deep relaxation for 10 minutes. The participants wore clothing appropriate to physical activity and sport shoes throughout the intervention. The intervention program was instructed, supervised and performed by one experienced physical education teacher, certified by Italian Ministry of Education.

Two days before the beginning of the intervention, participants performed the Verbal Paired Associates, a subtest of the Wechsler Memory Scale - IV, which represents one of the most widely used instruments for assessing explicit episodic memory performance. The participants completed the test immediately prior to and following the intervention, at the same time of the day and under the same experimental conditions in order to allow pre- and post-testing data connection and to evaluate the effects of the intervention program. Students were tested individually and all trials were performed using a standardized test protocol, observing the same conditions.

\section{Measures}

The Wechsler Memory Scale - IV

The Wechsler Memory Scale fourth edition (WMS-IV, 2009) is a well-validated and reliable neuropsychological test designed to measure different memory functions in people aged from 16 to 90 . It is made up of seven subtests: Brief Cognitive Status Exam, Spatial Addition, Symbol Span, Design Memory (I \& II), Logical Memory (I \& II), Verbal Paired Associates (I \& II), and Visual Reproduction (I \& II). The operator can choose to use all of them, some specific or just one. Relating to four subtests there is a form of immediate (I) or deffered (II) administration. In this study, Authors decided to use the Verbal Paired Associates I \& II. This subtest is one of the most widely used instruments for assessing explicit episodic memory performance. It measures relational memory of word pairs over repeated learning trials. In VPA I the tester read aloud a list of 14 word-pairs to the participant. After the presentation of the list of pairs, the tester said the first word of each pair and the respondent was required to provide its associate. The procedure was repeated 4 times, the same 14 word-pairs was used but varying the order of the word pairs for each trial. Approximately 20 minutes after completing VPA I, VPA II was administered. In this trial the tester read out the first word of each pair and the examinee was to recall which word was paired with it without hearing the word-pairs again. The system for calculating the score was for both VPA I and VPA II the number of correctly recalled words. It includes 1 point for each correct answer and 0 for each incorrect answer. Testing time was between 45 and 60 minutes, including the instruction and practice phase. Assessment protocol has been proposed a day before the beginning of the phase of observation and a day after the end of the intervention, in order to analyse any changes.

\section{Exercise training intervention}

The exercise intervention program was composed of different group of physical activities that included: flexibility, aerobic exercise, motor skills exercises, cardio dance workout and game. It was designed to be 
enjoyable and appealing by allowing participants to use their favorite music in the exercise sessions. Each round of exercise session included 10 -minute warm-up, moderate to vigorous physical activity, and 10-minute cool-down.

Various physical activities were used in order to maintain the motivation and the adherence in the program of each participants. The activities carried out were: joint mobility exercises, bodyweight exercises, group exercises, circuits, calisthenics basic workout, pilates exercises, exercise stations, cardio dance workout, zumba, and tag and ball games.

The intervention program started with a 10 minutes of warm-up sequence. The purpose of the warm-up was to prepare the student mentally and physically for the conditioning exercise that followed and to reduce the risk of injury. Warm-up included the following exercises: marching in place, wide toe touch, leg swings, arm swings, half jacks, chest expansions, torso rotation, alt back expansions, shoulder rotations, hops on the spots, single-leg hops, hip rotations, walking jacks, hip circles, walking knee hugs, side shuffles.

Each training session ended with a brief full-body relaxation and cool-down exercises. It consisted in a sequence of static stretching exercises which included glute stretch, standing quad stretch, piriformis stretch, side bench stretch, arm-cross shoulder stretch, overhead triceps stretch, lower back stretch, abdominal stretch, lunge with spinal twist, butterfly stretch, seated shoulder squeeze, child pose, breathing exercises. It was important for muscle relaxation and the improvement of joint range of motion.

\section{Statistical analysis}

We carried out statistical analyses using SAS JMP® Statistics (Version <14.3>, SAS Institute Inc., Cary, NC, USA, 2018). We presented data as group mean (M) values and standard deviations (SD) and checked for assumptions of normality (i.e. Shapiro-Wilk test) and homogeneity of variances (i.e. Levene test) in the data distributions. We used an independent sample $t$-test to evaluate group differences at baseline and a two-way ANOVA (group (experimental/control) $\times$ time (pre/post-intervention), with repeated measures on the time dimension, was conducted to examine the effect of the Multilateral Training on all dependent variables. When 'Group x Time' interactions reached significance, group-specific post hoc tests (i.e., paired $t$-tests) were conducted to identify the significant comparisons. Partial eta squared $\left(\eta^{2} p\right)$ was used to estimate the magnitude of the significant 'Time $x$ Group' interaction and interpreted using the following criteria: small $\left(\eta^{2} p\right.$ $<0.06)$, medium $\left(0.06 \leq \eta^{2} p<0.14\right)$, large $\left(\eta^{2} p \geq 0.14\right)$. Effect sizes for the pairwise comparisons were determined by Cohen's $d$ and interpreted as small $(0.20 \leq d<0.50)$, moderate $(0.50 \leq d<0.79)$ and large $(d \geq 0.80)$ (Cohen, 1992). Statistical significance was set at $p<.05$.

\section{RESULTS}

Table 1. Changes in long-term memory after an 8-week outdoor program.

\begin{tabular}{|l|c|c|c|c|c|c|c|}
\hline & \multicolumn{3}{c|}{ Experimental Group $(\mathbf{n}=15)$} & \multicolumn{3}{c|}{ Control Group ( $\mathbf{n = 1 5})$} \\
\hline & Baseline & Post-test & $\Delta$ & Baseline & Post-test & $\Delta$ \\
\hline Wechsler Memory Scale - IV \\
\hline Verbal Paired Associates I & 28.35 & 32.80 & 4.45 & 26.75 & 25.40 & -1.35 \\
& $(4.42)$ & $(4.29) \dagger^{*}$ & $(1.39)$ & $(4.08)$ & $(3.85)$ & $(1.46)$ \\
\hline Verbal Paired Associates II & 8.00 & 10.95 & 2.95 & 7.60 & 6.25 & -1.35 \\
& $(2.49)$ & $(2.06) \dagger^{*}$ & $(1.27)$ & $(2.30)$ & $(2.17)$ & $(1.59)$ \\
\hline
\end{tabular}

Note: values are presented as mean ( \pm SD); $\Delta$ : pre- to post-training changes; †Significant 'Group x Time' interaction: significant effect of the intervention $(p<.001)$. *Significantly different from pre-test $(p<.001)$. 
All subjects received the treatment conditions as allocated and completed the training program. No injuries were resulting from neither training program.

The experimental and control groups did not differ significantly at baseline in age, anthropometric characteristics, as well as in psychological measures ( $p>.05$ ) (Table 2). Pre and post-intervention results for all dependent measures are presented in Table 1.

\section{Verbal paired associates I}

Statistical analysis revealed significant 'Time x Group' interaction for Generalized self-efficacy scale $\left(F_{1,38}=\right.$ 164.94, $p<.001, \eta^{2} p=0.81$, large effect size). The post-hoc analysis revealed a significant improvement in the score for this cognitive skill ( $t=14.27, p<.001, d=3.18$, large effect size) in the intervention group. No significant changes were found for the control group $(p>.05)$.

\section{Verbal paired associates II}

Statistical analysis revealed significant 'Time $x$ Group' interaction for Generalized self-efficacy scale $\left(F_{1,38}=\right.$ 88.38, $p<.001, \eta^{2} p=0.69$, large effect size). The post-hoc analysis revealed a significant improvement in the score for this cognitive skill ( $t=10.33, p<.001, d=2.31$, large effect size) in the intervention group. No significant changes were found for the control group $(p>.05)$.

\section{DISCUSSION}

The purpose of this study was to investigate the relationship between an 8-week extracurricular outdoor physical activity program on long-term memory among students who must observe a forced rest because of the Covid-19 confinement.

In this research, the results indicate that a brief green exercise program was effective in improving episodic long-term memory. In particular, they suggested that a moderate to vigorous aerobic exercise has a direct and positive impact on the words recall ability previously acquired.

In fact, the most important finding which positively connects aerobic exercise with explicit episodic memory concerned the fact that students showed better ability to recall words as much in immediate trials (PVA I) as during deffered trial (PVA II). It reflects the ability to hold in mind in non-transitory way but relatively stable the information acquired. Given that, this exercise benefit was observed a day later the end of the intervention program, it seems likely that the memory benefits that were observed were due to the ability in the maintenance of information over time associated with the consolidation of memories that was affected. Specifically, we believe that the relationship between outdoor physical activity and improvement of long-term memory could be founded in the 2 mainly factors which characterized this green exercise program, namely the aerobic component of physical exercise, and the participation to complex physical activity that required greater cognitive involvement. In connection with this, previously research supported the idea that aerobic exercise is able to stimulates hippocampal neurogenesis and consequently improves episodic memory (Alam et al., 2018; Loprinzi et al., 2019, 2020). Several scientific evidence suggests that aerobic exercise increases brain derived neurotrophic factor (BDNF) which is a peripheral indicator of hippocampal neurogenesis (Bekinschtein et al., 2011; Leal et al., 2017) whose increase is correlated with improved memory function (Fu et al. 2017). Researchers indicated that higher intensity exercises elicit greater BDNF levels, thus it has been identified as a potential mechanism for the effects of exercise on memory (Cefis et al., 2019; Etnier et al., 2016; Saucedo Marquez et al., 2015; Schmidt-Kassow et al. 2012). 
Likewise, the motivational component and the solicitation of social skills in a moment of enforced isolation could be the elements that allowed students when interacted with peers to be especially susceptible to learn (Xiang et al., 2020). Moreover, exercising in natural environment, provided added value to these beneficial effects, through a positive and strong connection between physical activity and nature. The deep relationship between open-air physical activity and long-term memory has been widely accepted in scientific literature (Lahart et al., 2019; Suwabe et al., 2017).

Knight (2013) in her study, outlined that children who experienced outdoor teaching over regular intervals of one school day per week in the forest showed a higher academic performance than their peers in the school building. Their outdoor-learning program included chances to be physically active during curricular lessons planned by the teachers. Thompson Coon et al. (2011) argued that exercising in a natural environment, rather than in built environments indoors, reduces symptoms of distress and interpersonal difficulties, as well as decreases in tension, and confusion. Moreover, researchers found that the greater time spent doing green exercise, the greater improvements in learning (Colella, \& d'Arando, 2021). Those impacts were greatly increased when there was engaging in complex physical activity (Donnelly et al., 2016).

Based on what was discussed it was possible to claim that the findings of the previous research support our hypothesis, according to which students had significantly improved their episodic long-term memory, and at the same time had the opportunity to revitalize their mind and body and found resilience to stress following the outdoor physical activity intervention. Moreover, this brief program represented an extraordinary opportunity to escape from the daily routine lived at home within the walls, which they were forced due to Covid-19 pandemic (Raiola et al., 2020).

Despite the contribution regarding the significant relationship between outdoor physical activity and long-term memory some limitations were present within this study. First was related to the small sample size $(N=40)$ generated to the difficulties in recruiting students to participate due to the reluctance of parents feared to expose their children to contagion risks. Moreover, the sample was recruited from a population of students at local public school, therefore the results may not be generalizable. A second limitation concerned the fact that we did not evaluate the long-term effects of exercise on long-term memory and the lack of psychosocial measures, such as the assessment of participants' enjoyment, and resilience to stress. Future research would need to examine these possibilities in order to explain these variables. However, the results obtained could provide important indications for future studies. In fact, the strengths of this study were represented by the beneficient approach that this simple and effective program brings for the improvement of learning ability and consequently for academic achievement. Thus, Educational Institutions must acknowledge the importance of green physical activity in order to encourages the child to be physically active and at the same time promotes their facilitate learning, as well as physical and mental well-being.

\section{CONCLUSION}

This study suggests that aerobic exercise is an effective intervention able to increase the student's episodic long-term memory. It is a vehicle to promote a range of outcomes important to adolescents' qualitative growth. Indeed, it provided a positive and significant impact on sedentary lifestyle.

The COVID-19 pandemic, due to its unprecedented scale and unique response strategies, has had a critical impact on children's physical fitness as well as academic performance, particularly for those who have not practiced physical activity. Thus, we believe that this program was important to facilitate learning, as well as physical and mental well-being. 
The above evidence suggests that a green program that encourages the child to be physically active, promotes activities that include a combination of aerobic movement and complex physical activity with greater cognitive involvement, which allows to reach a higher academic performance level.

\section{AUTHOR CONTRIBUTIONS}

Author 1 designed the study, conducted the research, collected data, carried out the statistical analysis, was involved in the interpretation of data, wrote and revised the manuscript. Author 2 collected data, was involved in the interpretation of data and revised the manuscript. Author 3 collected data, was involved in the interpretation of data and revised the manuscript. Author 4 coordinated the study, interpreted the data and revised the manuscript. All authors contributed intellectually to the manuscript, and all authors have read the manuscript and approved the submission.

\section{REFERENCES}

Alam, M.J., Kitamura, T., Saitoh, Y., Ohkawa, N., Kondo, T., \& Inokuchi, K. (2018). Adult Neurogenesis Conserves Hippocampal Memory Capacity. The Journal of neuroscience: the official journal of the Society for Neuroscience, 38(31), 6854-6863. https://doi.org/10.1523/JNEUROSCl.2976-17.2018

Bekinschtein, P., Oomen, C. A., Saksida, L.M., and Bussey, T.J., (2011). Effects of environmental enrichment and voluntary exercise on neurogenesis, learning and memory, and pattern separation: BDNF as a critical variable? Seminars in Cell and Developmental Biology, 22(5): 536-542. https://doi.org/10.1016/j.semcdb.2011.07.002

Bianco, A., Patti, A., Bellafiore, M., Battaglia, G., Sahin, F.N., Paoli, A., Cataldo, M.C., Mammina, c., \& Palma, A. (2014). Group fitness activities for the elderly: an innovative approach to reduce falls and injuries. Aging clinical and experimental research, 26(2), 147-152. https://doi.org/10.1007/s40520013-0144-4

Bidzan-Bluma, I., \& Lipowska, M. (2018). Physical Activity and Cognitive Functioning of Children: A Systematic Review. International journal of environmental research and public health, 15(4), 800. https://doi.org/10.3390/ijerph15040800

Bonavolontà, V., Cataldi, S., Conenna, A., \& Fischetti, F. (2021a). Linking psycho-physical profiles to different training condition during COVID-19 confinement. Journal of Human Sport and Exercise, 16(2proc), S000-S000. https://doi.org/10.14198/ihse.2021.16.Proc2.57

Bonavolontà, V., Greco, F., Sabatini, U., Saavedra, F.J., Fischetti, F., Baldari, C., Guidetti, L., Vaccaro, M.G., \& Emerenziani, G.P. (2021b). Effects of Ballroom Dance on Physical Fitness and Reaction Time in Experienced Middle-Aged Adults of Both Genders. International Journal of Environmental Research and Public Health, 18(4), 2036. https://doi.org/10.3390/ijerph18042036

Bonavolontà, V., Cataldi, S., Maci, D., \& Fischetti, F. (2020). Physical activities and enjoyment during the lockdown: Effect of home-based supervised training among children and adolescents. Journal of Human Sport and Exercise, 15(4), 1338-1343. https://doi.org/10.14198/jhse.2020.15.Proc4.31

Cassilhas, R.C., Tufik, S., \& de Mello, M.T. (2016). Physical exercise, neuroplasticity, spatial learning and memory. Cellular and molecular life sciences: CMLS, 73(5), 975-983. https://doi.org/10.1007/s00018-015-2102-0

Cefis, M., Prigent-Tessier, A., Quirié, A., Pernet, N., Marie, C., \& Garnier, P. (2019). The effect of exercise on memory and BDNF signaling is dependent on intensity. Brain structure \& function, 224(6), 19751985. https://doi.org/10.1007/s00429-019-01889-7

Cohen, J. (1992). A Power Primer. Psychological Bulletin, 112(1), 155-159. https://doi.org/10.1037/0033$\underline{2909.112 .1 .155}$ 
Colella, D., \& d'Arando, C. (2021). Teaching styles and outdoor education to promote non-linear learning. JPES - Journal of Physical Education and Sport, 21(1), 507-513. https://doi.org/10.7752/ipes.2021.s1054

Cooper, C., Moon, H. Y., \& van Praag, H. (2018). On the Run for Hippocampal Plasticity. Cold Spring Harbor perspectives in medicine, 8(4), a029736. https://doi.org/10.1101/cshperspect.a029736

Donnelly, J.E., Hillman, C.H., Castelli, D., Etnier, J.L., Lee, S., Tomporowski, P., Lambourne, K., \& Szabo-Reed, A.N. (2016). Physical Activity, Fitness, Cognitive Function, and Academic Achievement in Children: A Systematic Review. Medicine and science in sports and exercise, 48(6), 1197-1222. https://doi.org/10.1249/MSS.0000000000000901

Dwyer, M.J., Pasini, M., De Dominicis, S., \& Righi, E., (2020). Physical activity: Benefits and challenges during the COVID-19 pandemic. Scandinavian journal of medicine \& science in sports, 30(7), 1291 1294. https://doi.org/10.1111/sms.13710

Erickson, K.I., Hillman, C., Stillman, C.M., Ballard, R.M., Bloodgood, B., Conroy, D.E., Macko, R., Marquez, D.X., Petruzzello, S.J., Powell, K.E., \& for 2018 Physical Activity Guidelines Advisory Committee (2019). Physical Activity, Cognition, and Brain Outcomes: A Review of the 2018 Physical Activity Guidelines. Medicine and science in sports and exercise, 51(6), 1242-1251. https://doi.org/10.1249/MSS.0000000000001936

Erickson, K.I., Voss, M.W., Prakash, R.S., Basak, C., Szabo, A., Chaddock, L., Kim, J.S., Heo, S., Alves, H., White, S.M., Wojcicki, T.R., Mailey, E., Vieira, V.J., Martin, S.A., Pence, B.D., Woods, J.A., McAuley, E., \& Kramer, A.F. (2011). Exercise training increases size of hippocampus and improves memory. Proceedings of the National Academy of Sciences of the United States of America, 108(7), 3017-3022. https://doi.org/10.1073/pnas.1015950108

Etnier, J.L., Wideman, L., Labban, J.D., Piepmeier, A.T., Pendleton, D.M., Dvorak, K.K., \& Becofsky, K., (2016). The Effects of Acute Exercise on Memory and Brain-Derived Neurotrophic Factor (BDNF). Journal of sport \& exercise psychology, 38(4), 331-340. https://doi.org/10.1123/jsep.2015-0335

Fischetti, F., Cataldi, S., \& Greco, G. (2019a). A combined plyometric and resistance training program improves fitness performance in 12 to 14 -years-old boys. Sport Sciences for Health, 15(3), 615-621. https://doi.org/10.1007/s11332-019-00560-2

Fischetti, F., Cataldi, S., \& Greco, G. (2019b). Lower-limb plyometric training improves vertical jump and agility abilities in adult female soccer players. Journal of Physical Education and Sport, 19(2), 12541261. https://doi.org/10.7752/jpes.2019.02182

Fischetti, F., Greco, G., Cataldi, S., Minoia, C., Loseto, G., \& Guarini, A., (2019). Effects of physical exercise intervention on psychological and physical fitness in lymphoma patients. Medicina (Lithuania), 55(7). https://doi.org/10.3390/medicina55070379

Fleshner, M. (2000). Exercise and neuroendocrine regulation of antibody production: protective effect of physical activity on stress-induced suppression of the specific antibody response. International Journal of Sports Medicine, 21(suppl 1):S14-S19. https://doi.org/10.1055/s-2000-1454

Fu, Y., Zhang, Y., \& Yuan, Q., (2017). Aerobic exercise ameliorates learning and memory deficits of aging rats induced by D-galactose via promoting SYP and BNDF expression in hippocampus. In BIO Web Conf. 8: 01020. EDP Sciences. https://doi.org/10.1051/bioconf/20170801020

Greco, G., Patti, A., Cataldi, S., lovane, A., Messina, G., \& Fischetti, F. (2019). Changes in physical fitness in young female volleyball players after an 8-week in-season pilates training program. Acta Medica Mediterranea, 35(6), 3375-3381. https://doi.org/10.19193/0393-6384_2019_6_531

Hötting, K., \& Röder, B. (2013). Beneficial effects of physical exercise on neuroplasticity and cognition. Neuroscience and biobehavioral reviews, 37(9 Pt B), 2243-2257. https://doi.org/10.1016/j.neubiorev.2013.04.005 
Jorgensen, L.G., Nowak, M., Ide, K., Secher, N.H. Cerebral blood flow and metabolism. In: Saltin B, Boushel R, Secher N, Mitchell J, eds. Exercise and Circulation in Health and Disease. Champaign, IL: Human Kinetics Publishers; 2000:113-236.

Khan, N.A., \& Hillman, C.H. (2014). The relation of childhood physical activity and aerobic fitness to brain function and cognition: a review. Pediatric exercise science, 26(2), 138-146. https://doi.org/10.1123/pes.2013-0125

Knight. Forest School and Outdoor Learning in the Early Years. SAGE Publications Ltd, 2013.

Labban, J.D., \& Etnier, J.L. (2018). The Effect of Acute Exercise on Encoding and Consolidation of LongTerm Memory. Journal of sport \& exercise psychology, 40(6), 336-342. https://doi.org/10.1123/isep.2018-0072

Lahart, I., Darcy, P., Gidlow, C., \& Calogiuri, G. (2019). The Effects of Green Exercise on Physical and Mental Wellbeing: A Systematic Review. International journal of environmental research and public health, 16(8), 1352. https://doi.org/10.3390/ijerph16081352

Latino, F., Cataldi, S., Fischetti, F. (2021). Effects of a Coordinative Ability Training Program on Adolescents' Cognitive Functioning. Frontiers In Psychology - 12, pp.1-8. ISSN:1664. https://doi.org/10.3389/fpsyg.2021.620440

Latino, F., Greco, G., Fischetti, F., \& Cataldi, S. (2019). Multilateral training improves body image perception in female adolescents. Journal of Human Sport and Exercise, 14(Proc4), S927-S936. https://doi.org/10.14198/ihse.2019.14.Proc4.55

Leal, G., Bramham, C.R., \& Duarte, C.B., (2017). BDNF and Hippocampal Synaptic Plasticity. Vitamins and hormones, 104, 153-195. https://doi.org/10.1016/bs.vh.2016.10.004

Lesser, I.A., \& Nienhuis, C.P. (2020). The Impact of COVID-19 on Physical Activity Behavior and WellBeing of Canadians. International journal of environmental research and public health, 17(11), 3899. https://doi.org/10.3390/ijerph17113899

Loprinzi, P.D., McRaney, K., Luca, K., \& McDonald, A. (2019). Exercise and Episodic Specificity Induction on Episodic Memory Function. Medicina (Kaunas, Lithuania), 55(8), 422. https://doi.org/10.3390/medicina55080422

Loprinzi, P.D., Moore, D., \& Loenneke, J.P. (2020). Does Aerobic and Resistance Exercise Influence Episodic Memory through Unique Mechanisms?. Brain sciences, 10(12), 913. https://doi.org/10.3390/brainsci10120913

McEwen, S.C., Siddarth, P., Rahi, B., Kim, Y., Mui, W., Wu, P., Emerson, N.D., Lee, J., Greenberg, S., Shelton, T., Kaiser, S., Small, G.W., \& Merrill, D.A. (2018). Simultaneous Aerobic Exercise and Memory Training Program in Older Adults with Subjective Memory Impairments. Journal of Alzheimer's disease: JAD, 62(2), 795-806. https://doi.org/10.3233/JAD-170846

Morano, M., Robazza, C., Ruiz, M. C., Cataldi, S., Fischetti, F., \& Bortoli, L. (2020). Gender-typed sport practice, physical self-perceptions, and performance-related emotions in adolescent girls. Sustainability (Switzerland), 12(20), 1-13. https://doi.org/10.3390/su12208518

Notarnicola, A., Vicenti, G., Fischetti, F., Laricchia, L., Guastamacchia, R., Tafuri, S., \& Moreti, B. (2012). Improved mental representation of space in beginner orienteers. Perceptual and Motor Skills, 114(1), 250-260. https://doi.org/10.2466/03.04.11.PMS.114.1.250-260

Park, S., Kim, B., \& Lee, J. (2020). Social Distancing and Outdoor Physical Activity During the COVID19 Outbreak in South Korea: Implications for Physical Distancing Strategies. Asia-Pacific journal of public health, 32(6-7), 360-362. https://doi.org/10.1177/1010539520940929

Patti, A., Zangla, D., Sahin, F. N., Cataldi, S., Lavanco, G., Palma, A., \& Fischetti, F. (2021). Physical exercise and prevention of falls. effects of a pilates training method compared with a general physical activity program: A randomized controlled trial. Medicine, 100(13), e25289. https://doi.org/10.1097/MD.0000000000025289 
Pesce, C., Crova, C., Cereatti, L., Casella, R., \& Bellucci, M. (2009). Physical activity and mental performance in preadolescents: Effects of acute exercise on free-recall memory. Mental Health and Physical Activity, 2(1), 16-22. https://doi.org/10.1016/i.mhpa.2009.02.001

Pinho, C. S., Caria, A., Aras Júnior, R., \& Pitanga, F. (2020). The effects of the COVID-19 pandemic on levels of physical fitness. Revista da Associacao Medica Brasileira (1992), 66Suppl 2(Suppl 2), 3437. https://doi.org/10.1590/1806-9282.66.S2.34

Pyke, W., Ifram, F., Coventry, L., Sung, Y., Champion, I., \& Javadi, A.H. (2020). The effects of different protocols of physical exercise and rest on long-term memory. Neurobiology of learning and memory, 167, 107128. https://doi.org/10.1016/i.nlm.2019.107128

Raiola, G., Aliberti, S., Esposito, G., Altavilla, G., D'Isanto, T., \& D'Elia, F., (2020). How has the Practice of Physical Activity Changed During the COVID-19 Quarantine? A Preliminary Survey. Teoriâ ta Metodika Fìzičnogo Vihovannâ, 20 (4), 242-247. https://doi.org/10.17309/tmfv.2020.4.07

Roberts, C. E., Phillips, L. H., Cooper, C. L., Gray, S., \& Allan, J. L. (2017). Effect of Different Types of Physical Activity on Activities of Daily Living in Older Adults: Systematic Review and Meta-Analysis. Journal of aging and physical activity, 25(4), 653-670. https://doi.org/10.1123/japa.2016-0201

Saucedo Marquez, C.M., Vanaudenaerde, B., Troosters, T., \& Wenderoth, N., (2015). Highintensity interval training evokes larger serum BDNF levels compared with intense continuous exercise. Journal of Applied Physiology, 119(12): 1363-1373. https://doi.org/10.1152/japplphysiol.00126.2015

Schmidt-Kassow, M., Schädle, S., Otterbein, S., Thiel, C., Doehring, A., Lötsch, J., and Kaiser, J. 2012. Kinetics of serum brain-derived neurotrophic factor following low-intensity versus high-intensity exercise in men and women. Neuroreport, 23(15): 889-893. https://doi.org/10.1097/WNR.0b013e32835946ca

Singh, A.S., Saliasi, E., van den Berg, V., Uijtdewilligen, L., de Groot, R., Jolles, J., Andersen, L.B., Bailey, R., Chang, Y.K., Diamond, A., Ericsson, I., Etnier, J.L., Fedewa, A.L., Hillman, C.H., McMorris, T., Pesce, C., Pühse, U., Tomporowski, P.D., \& Chinapaw, M., (2019). Effects of physical activity interventions on cognitive and academic performance in children and adolescents: a novel combination of a systematic review and recommendations from an expert panel. British journal of sports medicine, 53(10), 640-647. https://doi.org/10.1136/bjsports-2017-098136

Suwabe, K., Hyodo, K., Byun, K., Ochi, G., Fukuie, T., Shimizu, T., Kato, M., Yassa, M. A., \& Soya, H. (2017). Aerobic fitness associates with mnemonic discrimination as a mediator of physical activity effects: evidence for memory flexibility in young adults. Scientific reports, 7(1), 5140. https://doi.org/10.1038/s41598-017-04850-y

Thompson Coon, J., Boddy, K., Stein, K., Whear, R., Barton, J., \& Depledge, M.H., (2011). Does participating in physical activity in outdoor natural environments have a greater effect on physical and mental wellbeing than physical activity indoors? A systematic review. Environmental science \& technology, 45(5), 1761-1772. https://doi.org/10.1021/es102947t

Voelcker-Rehage, C., \& Niemann, C., (2013). Structural and functional brain changes related to different types of physical activity across the life span. Neuroscience and biobehavioral reviews, 37(9 Pt B), 2268-2295. https://doi.org/10.1016/j.neubiorev.2013.01.028

Voss, M.W., Soto, C., Yoo, S., Sodoma, M., Vivar, C., \& van Praag, H. (2019). Exercise and Hippocampal Memory Systems. Trends in cognitive sciences, 23(4), 318-333. https://doi.org/10.1016/j.tics.2019.01.006

Wechsler, D. (2009). Wechsler Memory Scale - Fourth Edition (WMS-IV) technical and interpretive manual. San Antonio, TX: Pearson.

WHO guidelines on physical activity and sedentary behaviour: at a glance. Geneva: World Health Organization; 2020. Licence: CC BY-NC-SA 3.0 IGO. ISBN 978-92-4-001487-9 (print version). 
Williams, A.M., Davis, K., \& Williams, J.G. (2000). Visual perception and action in sport. London: Spon Press. pp. 96-142.

Wray, A., Martin, G., Ostermeier, E., Medeiros, A., Little, M., Reilly, K., \& Gilliland, J. (2020). Physical activity and social connectedness interventions in outdoor spaces among children and youth: a rapid review. Interventions pour favoriser l'activité physique et l'appartenance sociale chez les enfants et les jeunes dans des espaces extérieurs: revue rapide de la littérature. Health promotion and chronic disease prevention in Canada: research, policy and practice, 40(4), 104-115. https://doi.org/10.24095/hpcdp.40.4.02

Xiang, M., Zhang, Z., \& Kuwahara, K. (2020). Impact of COVID-19 pandemic on children and adolescents' lifestyle behavior larger than expected. Progress in cardiovascular diseases, 63(4), 531532. https://doi.org/10.1016/i.pcad.2020.04.013

Zuniga, K.E., Mueller, M., Santana, A. R., \& Kelemen, W.L. (2019). Acute aerobic exercise improves memory across intensity and fitness levels. Memory (Hove, England), 27(5), 628-636. https://doi.org/10.1080/09658211.2018.1546875 